Springer Link

Search $Q$ Log in

Published: 23 June 2021

\title{
Academic Collaboration \\ Recommendation for Computer Science Researchers Using Social Network Analysis
}

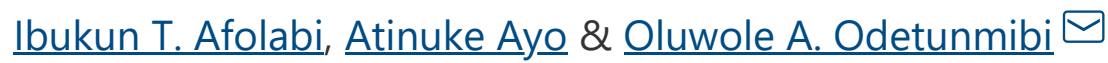

Wireless Personal Communications (2021)

8 Accesses $\mid \underline{\text { Metrics }}$

\section{Abstract}

In order to improve the quality and quantity of the performance in computing in Nigeria Universities, there is need for a functioning research networking application through which they can exchange ideas. This is because academics tend to be more comfortable communicating with each other, asking questions and more importantly, such networking will provide mentorship in the Nigeria academic

\section{Your privacy}

We use cookies to make sure that our website works properly, as well as some "optional" cookies to personalise content and advertising, provide social media features and analyse how people use our site. By accepting some or all optional cookies you give consent to the processing of your personal data, including transfer to third parties, some in countries outside of the European Economic Area that do not offer the same data protection standards as the country where you live. You can decide which optional cookies to accept by clicking on "Manage Settings", where you can also find more information about how your personal data is processed. View our privacy policy 
developed using the link prediction based on the Adamic-Adar Index measure. In conclusion, the result gotten from the network analysis is a valuable source of information for accessing the different centrality values of researchers in computer science. It also formed the foundation for developing an academic collaboration recommendation system for a small world research network. This will therefore improve the quantity and quality of performance of computer science academics in Nigeria.

This is a preview of subscription content, access via your institution.

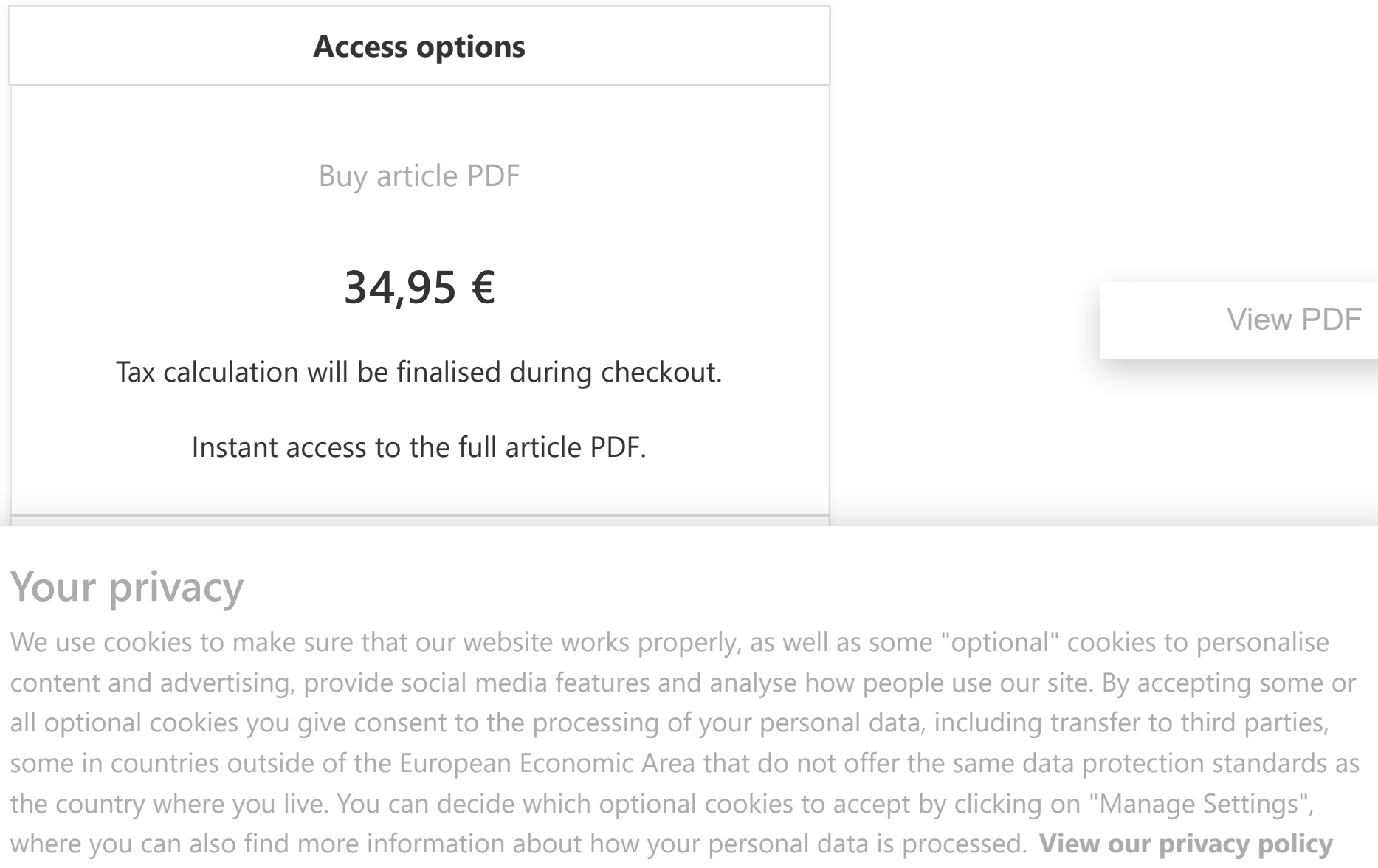




\section{Data Availability}

The data used for the research is available on request.

\section{Code Availability}

The code for analysing the data is available on request.

\section{References}

1. 1 .

Mattessich, P. M. C. (2001). Collaboration:

What makes it work (2nd ed.). Amherst

H.Wilder Foundation.

2. 2.

Lewis, J. (2010). Connecting and cooperating:

Social capital and public policy. UNSW Press.

3. 3 .

Okokpujie, I., Fayomi, O., Ogbonnaya, S., \&

n

- 4 ,...n mi

\section{Your privacy}

We use cookies to make sure that our website works properly, as well as some "optional" cookies to personalise content and advertising, provide social media features and analyse how people use our site. By accepting some or all optional cookies you give consent to the processing of your personal data, including transfer to third parties, some in countries outside of the European Economic Area that do not offer the same data protection standards as the country where you live. You can decide which optional cookies to accept by clicking on "Manage Settings", where you can also find more information about how your personal data is processed. View our privacy policy 
individual level. Research Policy, 29(1), 31-40.

5. 5 .

Theresa, C. O., \& Samson, O. C. (2017). Career-

training mentorship intervention via the

Dreyfus model: Implification for career

behaviors and practical skills acquisition in

vocational electronic technology. Journal of

Vocational Behavior, 103, 88-105.

6. 6 .

Ductor, L. (2014). Does co-authorship lead to higher academic productivity? Oxford Bulletin of Economics and Statistics, 77(3), 385-407.

7. 7 .

Kima, Y., Choib, T. Y., Yanb, T., \& Dooley, K.

(2011). Structural investigation of supply

networks: A social network analysis approach.

Journal of Operations Management, 29, 194-

211.

8. 8.

\section{Your privacy}

We use cookies to make sure that our website works properly, as well as some "optional" cookies to personalise content and advertising, provide social media features and analyse how people use our site. By accepting some or all optional cookies you give consent to the processing of your personal data, including transfer to third parties, some in countries outside of the European Economic Area that do not offer the same data protection standards as the country where you live. You can decide which optional cookies to accept by clicking on "Manage Settings", where you can also find more information about how your personal data is processed. View our privacy policy 
of the pacific asia conference on information

systems from 1993 to 2008. In Pacific Asia

Conference on Information Systems (pp. 1-13).

10. 10 .

Bruce Hoppe and Claire Reinelt. (2010). Social

network analysis and the evaluation of

leadership networks. The Leadership Quarterly, 21, 600-619.

11. 11.

Michael, F., \& Martina, K. M. (2010). The impact of network structure on knowledge transfer: an application of social network analysis in the context of regional innovation networks. The Annals of Regional Science, 44(1), 21-38.

12. 12 .

Manh, C. P., Yiwei, C., Ralf, K., \& Matthias, J. (2011). A clustering approach for collaborative filtering recommendation using social network analysis. Journal of Universal Computer

\section{Your privacy}

We use cookies to make sure that our website works properly, as well as some "optional" cookies to personalise content and advertising, provide social media features and analyse how people use our site. By accepting some or all optional cookies you give consent to the processing of your personal data, including transfer to third parties, some in countries outside of the European Economic Area that do not offer the same data protection standards as the country where you live. You can decide which optional cookies to accept by clicking on "Manage Settings", where you can also find more information about how your personal data is processed. View our privacy policy 
analysis measures. Journal of Informetrics, 3,

$594-607$.

14. 14 .

Tasleem, A., Rashid, A., \& Asger, M. (2012).

Scientific co-athorship social networks: A case

study of computer science scenario in India.

International Journal of Computer

Applications, 52(12), 38-45.

15. 15 .

Li, E. Y., Liao, C. H., \& Yen, H. R. (2013). Co-

authorship networks and research impact: A

social capital perspective. Research Policy,

42(9), 1515-1530.

16. 16 .

Tahereh, D., \& Stefano, N. (2017). Research

impact in co-authorship networks: a two-mode

analysis. Journal of Informetrics, 11, 371-388.

17. 17 .

Marion, E. H. (2017). Sport commmunication

\section{Your privacy}

We use cookies to make sure that our website works properly, as well as some "optional" cookies to personalise content and advertising, provide social media features and analyse how people use our site. By accepting some or all optional cookies you give consent to the processing of your personal data, including transfer to third parties, some in countries outside of the European Economic Area that do not offer the same data protection standards as the country where you live. You can decide which optional cookies to accept by clicking on "Manage Settings", where you can also find more information about how your personal data is processed. View our privacy policy 
density urban areas in China. Journal of

Cleaner Production, 198, 940-961.

19. 19 .

Yang, R. J., \& Zou, P. (2014). Stakeholder

associated risks and their interactions in

complex green building projects: A social

network model. Building of Environment, 73,

208-222.

20. 20 .

Jose, L. O. (2014). Influence of co-authorship

networks in the research impact: Ego network

analyses from microsoft academic search.

Journal of Informetrics, 8, 728-737.

21. 21.

William, R. (2006). Definitions of community.

Johns Hopkins Bloomberg, School of Public

Health, Johns Hopkins University.

22. 22.

Matthew, D. (2014). Social network analysis.

\section{Your privacy}

We use cookies to make sure that our website works properly, as well as some "optional" cookies to personalise content and advertising, provide social media features and analyse how people use our site. By accepting some or all optional cookies you give consent to the processing of your personal data, including transfer to third parties, some in countries outside of the European Economic Area that do not offer the same data protection standards as the country where you live. You can decide which optional cookies to accept by clicking on "Manage Settings", where you can also find more information about how your personal data is processed. View our privacy policy 
Bonacich, P. (1972). Factoring and weighting

approaches to status scores and clique

identification. Journal of Mathematical

Sociology, 2(1), 113-120.

25. 25 .

Fei, G., Katarzyna, M., Colin, C., \& Sophia, T.

(2015). Link prediction methods and their accuracy for different social networks and

network metrics. Scientific Programming .

https://doi.org/10.1155/2015/172879.

Funding

The authors appreciate Covenant University for sponsoring the publication of this article.

Author information

\section{Affiliations}

1 Dnnontmont of Commentonond Infonmotion

\section{Your privacy}

We use cookies to make sure that our website works properly, as well as some "optional" cookies to personalise content and advertising, provide social media features and analyse how people use our site. By accepting some or all optional cookies you give consent to the processing of your personal data, including transfer to third parties, some in countries outside of the European Economic Area that do not offer the same data protection standards as the country where you live. You can decide which optional cookies to accept by clicking on "Manage Settings", where you can also find more information about how your personal data is processed. View our privacy policy 


\section{Corresponding author}

Correspondence to Oluwole A. Odetunmibi.

\section{Ethics declarations}

\section{Conflict of interest}

There is no conflict of interest that is known to the authors.

\section{Additional information}

\section{Publisher's Note}

Springer Nature remains neutral with regard to

jurisdictional claims in published maps and

institutional affiliations.

Rights and permissions

$\underline{\text { Reprints and Permissions }}$

\section{Your privacy}

We use cookies to make sure that our website works properly, as well as some "optional" cookies to personalise content and advertising, provide social media features and analyse how people use our site. By accepting some or all optional cookies you give consent to the processing of your personal data, including transfer to third parties, some in countries outside of the European Economic Area that do not offer the same data protection standards as the country where you live. You can decide which optional cookies to accept by clicking on "Manage Settings", where you can also find more information about how your personal data is processed. View our privacy policy 
Wireless Pers Commun (2021).

https://doi.org/10.1007/s11277-021-08646-2

- Accepted15 June 2021

- Published23 June 2021

- DOIIhttps://doi.org/10.1007/s11277-021-08646-

$\underline{2}$

\section{Keywords}

- Social network analysis

- Link prediction

- Centrality measures

- Computer science

- Research collaboration

Not logged in - 197.210.64.12

Not affiliated

\section{SPRINGER NATURE}

\section{Your privacy}

We use cookies to make sure that our website works properly, as well as some "optional" cookies to personalise content and advertising, provide social media features and analyse how people use our site. By accepting some or all optional cookies you give consent to the processing of your personal data, including transfer to third parties, some in countries outside of the European Economic Area that do not offer the same data protection standards as the country where you live. You can decide which optional cookies to accept by clicking on "Manage Settings", where you can also find more information about how your personal data is processed. View our privacy policy 